\section{FRI0578 INCREASED VEIN WALL THICKNESS IN BEHÇET'S SYNDROME}

M. Gjoni ${ }^{1}$, E.S. Durmaz ${ }^{2}$, S. Akbaş ${ }^{2}$, A.S. Dikici' ${ }^{2}$ I. Mihmanlı ${ }^{2}$, H. YazıcI ${ }^{3}$, E. Seyahi ${ }^{3} .{ }^{1}$ Department of Medicine; ${ }^{2}$ Department of Radiology; ${ }^{3}$ Department of Medicine, Division of Rheumatology, Cerrahpaşa Medical Faculty, Istanbul, Turkey

Background: Lower extremity vein thrombosis (LEVT) is the key feature of vascular involvement in Behçet's syndrome (BS). Vein wall thickness (VWT) is proposed to be a surrogate marker of venous disease. A pilot MR study done in 7 BS patients and controls, had demonstrated increased VWT and signal enhancement in the lower extremity veins of BS patients without vascular disease. ${ }^{1}$ Another study, using USG, found that VWT was increased among BS patients without vascular disease compared to patients with ankylosing spondylitis and healthy controls. $^{2}$

Objectives: We reassessed VWT in proximal lower extremity veins in BS patients with LEVT and suitable controls in a formal, masked protocol.

Methods: We studied 47 (40 M/ 7 F) BS patients with LEVT, 50 (43 M/ 7 F) BS patients without any vascular involvement and $38(31 \mathrm{M} / 7 \mathrm{~F})$ age and gender matched apparently healthy controls. Two independent radiologists, blinded to the diagnosis of BS, used USG to measure VWT of common femoral vein (CFV), superficial femoral vein (SFV) and vena saphena magna (VSM) in both legs.

Results: As shown in table 1, mean age at disease onset and the disease duration were similar between BS study groups. The mean age at thrombosis onset of the patients with LEVT was $26.4 \pm 5.8$ years. There was good concordance between the 2 observers (kappa: 0.9 ) The mean VWT was significantly increased among both BS patients with LEVT and those without any vascular involvement when compared to the healthy controls while those with LEVT had the thickest veins.

Abstract FRI0578 - Table 1. Disease duration and VWT

\begin{tabular}{|c|c|c|c|c|}
\hline & $\begin{array}{l}\text { BS with vascular } \\
\text { involvement } \\
(n=47 ; 40 \mathrm{M} / 7 \mathrm{~F})\end{array}$ & $\begin{array}{c}\text { BS without vascular } \\
\text { involvement } \\
(n=50 ; 43 M / 7 F)\end{array}$ & $\begin{array}{l}\text { Healthy } \\
\text { controls } \\
(\mathrm{n}=38 ; \\
31 \mathrm{M} / 7 \mathrm{~F})\end{array}$ & $P$ value \\
\hline Age, years & $37.06 \pm 5.26$ & $36.98 \pm 4.47$ & $34.87 \pm 7.22$ & 0.296 \\
\hline $\begin{array}{l}\text { Disease duration } \\
\text { Vein wall thickness, } \\
\text { mean } \pm S D, m m\end{array}$ & $10.96 \pm 6.45$ & $9.68 \pm 5.89$ & - & 0.310 \\
\hline $\begin{array}{l}\text { Right CFV } 1 \text { st } \\
\text { observer }\end{array}$ & $0.91 \pm 0.67$ & $0.69 \pm 0.15$ & $0.57 \pm 0.11$ & 0.001 \\
\hline $\begin{array}{l}\text { Right CFV 2nd } \\
\text { observer }\end{array}$ & $0.93 \pm 0.76$ & $0.70 \pm 0.18$ & $0.58 \pm 0.09$ & $<0.001$ \\
\hline Left CFV 1 st observer & $1.04 \pm 0.85$ & $0.66 \pm 0.11$ & $0.56 \pm 0.07$ & $<0.001$ \\
\hline Left CFV 2nd observer & $1.09 \pm 0.83$ & $0.69 \pm 0.16$ & $0.57 \pm 0.07$ & $<0.001$ \\
\hline $\begin{array}{l}\text { Right SFV } 1 \text { st } \\
\text { observer }\end{array}$ & $0.79 \pm 0.38$ & $0.60 \pm 0.11$ & $0.51 \pm 0.9$ & $<0.001$ \\
\hline $\begin{array}{l}\text { Right SFV 2nd } \\
\text { observer }\end{array}$ & $0.80 \pm 0.42$ & $0.62 \pm 0.13$ & $0.52 \pm 0.07$ & $<0.001$ \\
\hline Left SFV 1 st observer & $0.88 \pm 0.38$ & $0.62 \pm 0.12$ & $0.49 \pm 0.09$ & $<0.001$ \\
\hline Left SFV 2nd observer & $0.90 \pm 0.40$ & $0.63 \pm 0.13$ & $0.51 \pm 0.07$ & $<0.001$ \\
\hline $\begin{array}{l}\text { Right VSM } 1 \text { st } \\
\text { observer }\end{array}$ & $0.60 \pm 0.22$ & $0.52 \pm 0.11$ & $0.43 \pm 0.07$ & $<0.001$ \\
\hline $\begin{array}{l}\text { Right VSM 2nd } \\
\text { observer }\end{array}$ & $0.64 \pm 0.25$ & $0.53 \pm 0.13$ & $0.46 \pm 0.08$ & $<0.001$ \\
\hline Left VSM 1 st observer & $0.67 \pm 0.23$ & $0.53 \pm 0.11$ & $0.42 \pm 0.09$ & $<0.001$ \\
\hline Left VSM 2nd observer & $0.65 \pm 0.27$ & $0.53 \pm 0.11$ & $0.43 \pm 0.07$ & $<0.001$ \\
\hline
\end{tabular}

CFV: common femoral vein, SFV: superficial femoral vein, VSM: vena saphena magna

Conclusions: VWT of proximal deep and superficial lower extremity veins was found to be increased among BS patients without any clinical and radiological vascular involvement.

\section{REFERENCES :}

[1] Ambrose $\mathrm{N}$, et al. Magnetic resonance imaging of vein wall thickness in patients with Behçet's syndrome. Clin Exp Rheumatol. 2014.

[2] Alibaz-Oner F, et al. Venous vessel wall thickness in lower extremity is increased in male behcet's disease patients without vascular involvement. Ann Rheum Dis 76(Suppl 2):417.

Disclosure of Interest: None declared

DOI: 10.1136/annrheumdis-2018-eular.4701

\section{FRI0579}

DIAGNOSTIC UTILITY OF METATARSOPHALANGEAL SYNOVITIS IDENTIFIED BY ULTRASONOGRAPHY FOR EARLY RHEUMATOID ARTHRITIS

M. Okamoto ${ }^{1}$, K. Fujikawa ${ }^{1}$, A. Mizokami ${ }^{1}$, Y. Endo ${ }^{2}$, M. Mine $^{3}$, A. Kawakami². ${ }^{1}$ Rheumatology, Isahaya General Hospital, Isahaya; ${ }^{2}$ Immunology and Rheumatology, Nagasaki University Graduate School of Biomedical Sciences, Nagasaki, ${ }^{3}$ Rheumatology, Suga Orthopedic Hospital, Isahaya, Japan

Background: In patients with rheumatoid arthritis (RA), synovitis can occur at not only hand and finger joints but also the metatarsophalangeal (MTP) joints. However, power Doppler ultrasonography (PDUS) findings of the MTP joints and its diagnostic utility remain unclear in patients with early RA.

Objectives: The present study investigated whether the detection of MTP synovitis by PDUS is useful for the diagnosis of early RA.

Methods: The study enrolled 174 patients with suspected RA within 6 months of onset. We assessed the articular synovium using grey scale (GS) and power Doppler (PD) signals with a semi-quantitative method (grades $0-3$ ) in both hand and finger joints ( 22 joints) and MTP joints ( 10 joints) by PDUS. In addition, we evaluated bone erosion and intermetatarsal bursitis. We defined GS grade $\geq 1$ and $P D$ grade $\geq 1$ as PDUS synovitis. We evaluated the diagnostic accuracy of PDUS synovitis for $R A$

Results: Of the 174 patients, 59 were diagnosed with RA and 115 did not have RA. Among the patients with RA, $47(80 \%)$ had PDUS synovitis in the hand and finger joints and $32(54 \%)$ had PDUS synovitis in the MTP joints. The frequencies of PDUS synovitis in each MTP joint, bone erosion of the fifth MTP joint, and intermetatarsal bursitis were significantly higher in patients with RA than in those without RA. The diagnostic accuracy of PDUS synovitis in the hand and finger joints was good, with a sensitivity of $80 \%$, specificity of $77 \%$, and accuracy of $78 \%$. On considering the MTP joints in addition to the hand and finger joints, the diagnostic accuracy improved, with a sensitivity of $92 \%$, specificity of $74 \%$, and accuracy of $80 \%$. In this study, 7 patients (12\%) with RA had synovitis in the MTP joints and not in the hand and finger joints.

Conclusions: When synovitis cannot be detected in the hand and finger joints by PDUS, scanning of the MTP joints could be useful for the diagnosis of early RA.

\begin{tabular}{c|c|c|c}
\hline & RA & non-RA & p-value \\
& $\mathrm{n}=59$ & $\mathrm{n}=115$ & $<0.001$ \\
\hline PDUS synovitis & $32 / 59(54 \%)$ & $5 / 115(4 \%)$ & $<0.001$ \\
$1^{\text {st }}$ MTP & $24 / 118(20 \%)$ & $7 / 230(3 \%)$ & $<0.001$ \\
$2^{\text {nd }}$ MTP & $16 / 118(14 \%)$ & $5 / 230(2 \%)$ & $<0.001$ \\
$3^{\text {tc }}$ MTP & $13 / 118(11 \%)$ & $3 / 230(1 \%)$ & $<0.001$ \\
$4^{\text {th }}$ MTP & $10 / 118(8 \%)$ & $0 / 230(0 \%)$ & $<0.001$ \\
$5^{\text {th }}$ MTP & $17 / 118(14 \%)$ & $0 / 230(0 \%)$ & $<0.001$ \\
\hline Bone erosion & $8 / 59(14 \%)$ & $0 / 115(0 \%)$ & 0.114 \\
$1^{\text {st }}$ MTP & $2 / 118(2 \%)$ & $0 / 230(0 \%)$ & 0.339 \\
$2^{\text {nd }}$ MTP & $1 / 118(1 \%)$ & $0 / 230(0 \%)$ & 1.000 \\
$3^{\text {rc }}$ MTP & $0 / 118(0 \%)$ & $0 / 230(0 \%)$ & 1.000 \\
$4^{\text {th }}$ MTP & $0 / 118(0 \%)$ & $0 / 230(0 \%)$ & 0.004 \\
$5^{\text {th }}$ MTP & $5 / 118(4 \%)$ & $0 / 230(0 \%)$ & 0.038 \\
\hline Intermetatarsal bursitis & $3 / 118(3 \%)$ & $0 / 230(0 \%)$ & Fisher's exactprobability test \\
\hline RA, rheumatoid arthitis & & &
\end{tabular}

Abstract FRI0579 - Figure 1. Power Doppler ultrasonography (PDUS) findings in the metatarsophalangeal (MTP) joints

RA, rheumatoid arthritis

Fisher's exact probability test

Disclosure of Interest: None declared

DOI: 10.1136/annrheumdis-2018-eular.4115 